\title{
Perspectivas de análise geográfica do patrimônio cultural: algumas reflexões
}

Resumo: Objetiva-se com este artigo delinear algumas reflexões do estudo geográfico de caráter cultural, demonstra um campo possível de estudo a partir da análise do patrimônio cultural e aponta novas perspectivas para a realização desta investigação. Tal estudo leva em consideração a importância que o aspecto cultural vem ganhando na análise das problemáticas geográficas, uma vez que apreciações pautadas apenas no caráter político e econômico, em algumas situações, não tem dado conta de compreendê-las. Objetiva-se ainda trazer uma contribuição para a ciência geográfica, notadamente ao ramo da geografia cultural em diálogo constante com áreas afins, como a história, a arquitetura e a antropologia.

\section{Prospects of geographical analysis of cultural heritage: some reflections}

\begin{abstract}
Objective with this article is to outline some of the reflections of cultural geographical study demonstrates a possible field of study based on the analysis of cultural heritage and points to new perspectives for conducting this research. This study takes into consideration the importance of the cultural aspect has gained in the analysis of geographical problems, since assessments guided only political and economic, in some situations, has not given account of understanding them. Another goal is to bring a contribution to geographical science, particularly the field of cultural geography in constant dialogue with related areas such as history, architecture and anthropology.
\end{abstract}

${ }^{*}$ Doutor em Geografia; Adjunto em História das cidades. Docente dos cursos de Graduação e Pós-Graduação da UFSM Universidade Federal de Santa Maria; Membro do COMPHIC Conselho Municipal Patrimônio Histórico Cultural; Membro do Grupo de Estudos CIDADHIS - Departamento de Arquitetura e Urbanismo da Universidade Federal de Santa Catarina; Membro da RELARQ-Rede Latino Americana de Documentação em Arquitetura e Urbanismo

\section{Palavras-chave:}

Geografia; Patrimônio cultural; Cultura;

Espaço urbano.

Key-Words:

Geography; Cultural heritage; Culture; 
A valorização do passado das cidades é uma característica comum às sociedades deste final de milênio. No Brasil, esta tendência é inédita e reflete uma mudança significativa nos valores e atitudes sociais até agora predominantes. Depois de um longo período em que só se cultuava o que era novo, um período que resultou num ataque constante e sistemático às heranças vindas de tempos antigos, eis que atualmente o cotidiano urbano brasileiro vê-se invadido por discursos e projetos que pregam a restauração, a preservação ou a revalorização dos mais diversos vestígios do passado.(ABREU,1998, p.01).

Este artigo nasceu do interesse em trazer uma reflexão sobre a temática do patrimônio visto como referência cultural dos grupos humanos, sinalizando assim novos horizontes consubstanciais e complementares na análise da dimensão geográfica da cultura. Na tradição geográfica, os bens culturais nunca foram objeto de análise, mas isso vem mudando nos últimos anos, sinalizando para um rico caminho teórico e investigativo a ser seguido no âmbito da própria ciência geográfica e em diálogo permanente com áreas afins, como a história, a arquitetura e a antropologia.

Nesse cenário, a cultura passa a ter uma nova importância na vida econômica e política contemporânea. $O$ desenvolvimento humano não é compreensível sem o reconhecimento do verdadeiro papel da criação cultural, em estreita ligação com a educação e a formação, com a investigação e a ciência. A cultura humana é que define e distingue o desenvolvimento e 0 atraso, a qualidade, a exigência, ou seja, a capacidade de aprender. Deixou de fazer sentido a oposição entre políticas públicas centradas no Patrimônio Histórico, por contrapondo à criação contemporânea. Obviamente que a complementaridade se faz necessária. Para tanto, basta um olhar de grande marcos da presença humana ao longo do tempo e perceber que há sempre uma simbiose de diversas influências, de diversas épocas, ligando Patrimônio material e imaterial, herança e criação.

Os apontamentos deste texto ganham uma interpretação geográfica, afinal, o patrimônio cultural e suas categorias de análise possuem uma expressão espacial constituída na própria identidade. Quando o espaço transpõe o tempo na memória social ele torna-se patrimônio, campo conflituoso de representações sócio-políticas. Trata-se de um balanço provisório e teórico, procurando dar densidade ás reflexões sobre o uso e ocupação do território a partir da patrimonialização.

O olhar do geógrafo inicia pela própria espacialidade, resultante da produção social. Pensar as lógicas dos bastidores desse processo é de fundamental importância cujo conhecimento empírico identifica rapidamente como paisagem, gerando importantes transformações sócio-espaciais.

A nova categoria, Paisagem Cultural, também ganha destaque nesta discussão uma vez que tem sido um instrumento importante em processos de tombamento. De sua proposição e evolução nas discussões geográficas o conceito foi apropriado pela UNESCO em 1992, para representar bens patrimoniais de relevância internacional no qual se manifestava uma influência clara e mútua entre ação humana e meio ambiente. Passava-se assim, de uma concepção de patrimônio bipartida entre bem natural e bem cultural, para uma noção de patrimônio misto, integrado e interdependente, num processo lento da consideração do valor cultural de paisagens naturais. Na mesma direção, o IPHAN - Instituto do Patrimônio Histórico e Artístico Nacional, ao inventariar patrimônios materiais ou imateriais, seleciona seus territórios, ou seja; é no espaço que se materializa a idéia do tombamento. E a geografia, que sempre trabalhou com esses conceitos espaciais, não pode ficar alheia desse processo.

Nesse cenário, pensar a cidade por esse viés equivale identificar as nuances do comportamento humano, na medida em que ela constitui-se em materialidade, em seus construtos patrimoniais - e imaterialidade, resultante dos símbolos e significados conferidos pelos diferentes atores sociais ao longo dos processos históricos. 0 lugar guarda essa perspectiva, entendido como 0 resultado de práticas sociais distintas e do sentimento de pertença que the é inerente. O lugar equivale a uma representação, pois existe no real e transcende a ele, sendo imageado pelos indivíduos, 
Um fator condicionante em relação à identificação de uma determinada porção do espaço enquanto lugar diz respeito ao processo de identificação e de reconhecimento que a população possui em relação aos espaços de sociabilidade e vivência cultural. Este sentimento de pertença identifica o apreço ou amor ao lugar, que se internaliza nos indivíduos à medida que ao se apropriarem do espaço, inserindo-o em seu cotidiano, reconhecem nele a própria extensão de sua vida.

É a partir deste entendimento que a dimensão geográfica da cultura deve abranger a compreensão do passado, presente e futuro, de modo que a memória seja revivida e respeitada, assumindo a relação que se estabelece entre as pessoas, a sociedade e a herança que recebem e que projetam no futuro.

Para compreender melhor essa tendência recente de busca de valoração do patrimônio, este artigo pretende discuti-la a partir de três eixos de análise. O primeiro é de natureza geral, busca conceituar o que se entende por patrimônio e suas relações com o espaço. 0 segundo retrata a importância dos estudos da paisagem pela geografia, sua proposição, evolução e a criação, desde 1992, da nova categoria de bem patrimonial, a paisagem cultural. Finalmente, o terceiro eixo objetiva discutir o valor de uso da preservação patrimonial sob o olhar geográfico.

\section{Espaço urbano e patrimônio}

A perspectiva cultural da geografia nem sempre foi fundamentada em uma concepção que identificasse e aprovasse as interações entre o homem e o espaço e suas marcas na paisagem enquanto manifestações culturais, sobre as varias manifestações e a diversidade cultural. Neste raciocínio ZANATA (2011, p. 230) ressalta que esta diversidade tomando por base os seus conteúdos materiais, admite que a cultura tenha uma relação íntima com o sistema de representações, de significados, de valores, que criam uma identidade que é manifestada perante construções compartilhadas socialmente e são expressas espacialmente. Ou seja, de aceitar que a cultura no seu sentido antropológico mais amplo representa todo o modo de vida de uma sociedade, o que não inclui somente a produção de objetos materiais, mas um sistema cultural (valores morais, éticos, hábitos e significados expressos nas práticas sociais), um sistema simbólico (mitos e ritos unificadores) e um sistema imaginário, que serve de liame aos dois últimos, constituindo-se no locus da construção da identidade espacial de um grupo. (ZANATA, 2011, p.231).

Deste modo a importância e o reconhecimento da paisagem culturalmente construída estão atrelados a valorização das ações humanas no seu processo de transformação. Ainda segundo ZANATA (2011, p.232), "a abertura dos novos horizontes para a análise da dimensão geográfica da cultura foi encontrada na revalorização de características fundamentais do humanismo. Assim, o homem foi recolocado no centro das preocupações dos geógrafos culturais, como produtor e produto de seu próprio mundo".

Em BURDA e MONASTIRSKY (2011), o patrimônio cultural compõe o espaço urbano manifestando seus traços históricos e a história das relações sociais. A preservação do patrimônio cultural contribui para o reconhecimento identitário do indivíduo -colabora para a integração deste com a própria sociedade - e possibilita o conhecimento cultural de um determinado lugar. No âmbito das discussões geográficas, tanto a Geografia Urbana quanto a Geografia Cultural, mesmo que recentes, os estudos patrimoniais (material e imaterial) vem analisando, com muita propriedade, de que forma os mesmos tem-se configurado nas cidades - organização e apropriação do espaço - e sobre o processo (muitas vezes conflituosos) da escolha desses patrimônios, a sua preservação (inclui-se também o restauro) e os seus usos. Estudos patrimoniais e da memória urbana como ABREU (1998), PAES-LUCHIARI (2005, 2005.a, 2006, 2012), MONASTIRSKY (2006, 2009, 2011), RIBEIRO (2008), FIGUEIREDO (2011, 2011.a), PIMENTA (1998, 2011), ZANIRATO E RIBEIRO (2006), reconhecem a importância e a riqueza desses estudos na atualidade, evidenciando um campo fértil aberto á novas direções da pesquisa geográfica. Merece destacar ainda o diálogo

Geografia Ensino \& Pesquisa, v. 17, n.1 p. 55-70, jan./abr. 2013

Figueiredo, L. C.

ISSN 2236-4994 
permanente e aberto entre geógrafos, arquitetos, historiadores e antropólogos. E é por esta razão que estudos dessa natureza têm dado cada vez mais atenção as multiplicidades espaciais, abrindo um leque á interdisciplinaridade, dando-lhes novos fôlegos, novas abordagens e novos resultados.

Em outra direção os estudos de LEFEBVRE (1976, p. 29-32), consideram o espaço geográfico como espaço vivido e como consequência da prática social dos habitantes ao longo da história. Este evidencia-se não só a partir dos edifícios tombados, mas também no Centro Histórico enquanto um espaço social, onde foi construído, produzido e projetado o espaço urbano. $\mathrm{O}$ autor acrescenta ainda quatro hipóteses para o espaço. A primeira é o espaço "puro", transparente e inteligível, liberto de ideologia, interpretação e sabedoria. A segunda refere-se ao espaço social, produto da sociedade, descrição empírica verificável e relatos, antes de qualquer teorização. Essa hipótese é adequada às questões sobre o patrimônio cultural arquitetônico, cujas edificações são produtos da sociedade (habitantes, turistas, patrimônio). Na terceira hipótese o espaço aparece como uma mediação, ou seja, um instrumento político, intencionalmente manipulador. 0 espaço como o mais importante de todos os instrumentos aprece na quarta hipótese, sendo o pressuposto de toda produção e de toda troca.

LEFÉVBRE (2011) adverte ainda que o que se conhece no momento é o aparecimento da real sociedade urbana, uma construção que se dá dialeticamente e conjuntamente com a expansão da cidade tradicional e da malha urbana historicamente instituída. A criação de novas necessidades e possibilidades no mundo do urbano, aliados à modernização da economia e da cultura, faz com que o direito à cidade seja temas fundamentais em constantes discussões. Porém, essas novas demandas devem estar aliadas à preservação, porque a sociedade urbana não deixa de ser resultado de construções passadas, não as devendo subestimar e sim a elas se complementar. Outra contribuição do autor diz respeito ao espaço social, onde este não deve ser visto como espaço absoluto, muito menos como criação da sociedade e nem ter fins políticos, para ele "o espaço é o lócus da reprodução das relações sociais de produção" (LEFÉBVRE, 1976, p. 27).

Em Milton Santos (2002), o espaço geográfico e sua formação pelo patrimônio urbano, explica-se pela noção de totalidade cujas partes se agregam no todo, não representando somente a soma das partes. Deste modo o patrimônio e sua totalidade se compõem pelo conjunto das edificações tombadas, a composição da paisagem cultural, as relações sociais deste espaço e os significados do patrimônio e da memória coletiva.

O patrimônio cultural compõe o espaço geográfico e se apresenta como um Ben importante na análise da sua organização. $O$ espaço geográfico historicamente produzido deve ser estudado a partir da sua funcionalidade e dos significados que os diversos elementos apresentam, através da composição do passado com o tempo presente. O patrimônio cultural-histórico é, portanto, constituído através dos estratos do tempo, mas, também, pelos 'olhares' do presente que, associados, compõem diversos desdobramentos conceituais sobre ele e sobre o espaço em que está inserido. (MONASTIRSKY, 2006, p. 17).

\section{Patrimônio e Identidade}

No decorrer do século XX o acelerado processo de urbanização fez com que a cidade e seus arredores passassem a ser apreendidos como um tecido vivo, composto por construções e por pessoas, incorporando ambientes do passado que podem ser mantidos e, ao mesmo tempo, agregados à dinâmica espacial. Tais dinâmicas tornaram-se um nível específico da prática social

Geografia Ensino \& Pesquisa, v. 17, n. 1 p. 55-70, jan./abr. 2013

Perspectivas de análise geográfica do patrimônio cultural: algumas reflexões na qual se vêem paisagens, arquiteturas, praças, ruas, formas de sociabilidade; um lugar não homogêneo e articulado, mas antes um mosaico muitas vezes sobreposto, que expressa tempos e modos diferenciados de viver. Essa compreensão implicou a valorização dos aspectos nos quais se plasma a cultura de um povo: as línguas, os instrumentos de comunicação, as relações sociais, os ritos, as cerimônias, os comportamentos coletivos, os sistemas de valores e crenças que passaram a ser vistos como referências culturais dos grupos humanos, signos que definem as culturas e que 
necessitavam salvaguarda. (ZANIRATO E RIBEIRO, 2006). Esses novos entendimentos levaram á constatação de que os signos das identidades de um povo não podem ser definidos tendo como referência apenas as culturas ocidentais, assim como a cultura campesina, não podem ser vista como menor diante das atividades industriais.

A cultura é o conjunto de atividades, modos de agir e costumes de um povo. É um processo em constante evolução, desenvolvido por um grupo social, uma nação, uma comunidade e é fruto do esforço coletivo pelo aprimoramento de valores espirituais e materiais. A importância da cultura no fortalecimento da identidade de um povo é definida pelo Instituto Estadual do Patrimônio Histórico e Artístico de Minas Gerais (IEPHA/ MG:2007, p. 11):

A cultura e a memória de um povo são os principais fatores de sua coesão e identidade, os responsáveis pelos liames que unem as pessoas em torno de uma noção comum de compartilhamento e identidade, noção básica para o senso de cidadania.

O patrimônio histórico cultural materializa e torna visivel esse sentimento evocado pela cultura e pela memória e, assim, permite a construção das identidades coletivas, fortalecendo os elos das origens comuns, passo decisivo para a continuidade e a sobrevivência de uma comunidade. Além desse aspecto de construção de identidade, a noção de patrimônio cultural diz respeito à herança coletiva que deve ser transmitida às futuras gerações, de forma a relacionar o passado e o presente, permitindo a visão do futuro. (Diretrizes para Proteção do Patrimônio Cultural, 2006, pág. 8).

O patrimônio cultural é um conjunto de todos os bens que, pelo seu valor próprio, devem ser considerados de interesse relevante para a permanência e a identidade da cultura de um povo. Pode ser classificado em dois grupos: bens materiais e bens imateriais. Os bens materiais por sua vez, estão divididos em bens móveis e imóveis. Os bens móveis compreendem a produção pictórica, escultórica, mobiliário e objetos. Os bens imóveis não se restringem ao edifício isolado, mas também seu entorno - o que garante a visibilidade e ambiência da edificação. Estão incluídos neste grupo os núcleos históricos e os conjuntos urbanos e paisagísticos. Por bens imateriais entende-se toda a produção cultural de um povo, desde sua expressão musical até sua memória oral.

A preservação do patrimônio cultural visa à continuidade das manifestações culturais, promove a melhoria da qualidade de vida da comunidade, implica na manutenção de seu bem estar material e espiritual e garante o exercício da cidadania. Devem ser preservados aqueles exemplares caracterizados por sua representatividade, bem como aqueles que contribuam para a manutenção dos conjuntos e ambiências. 0 conceito de patrimônio estende-se, portanto, aos conjuntos urbanos e às diversas manifestações de grupos e épocas em:

(...) oposição a uma seletividade que privilegiava os bens culturais produzidos pelas classes hegemônicas - pirâmides, palácios, objetos ligados à nobreza e à aristocracia reconhece-se que o patrimônio de uma nação também se compõe dos produtos da cultura popular: música indígena, textos de camponeses e operários, sistemas de autoconstrução e preservação dos bens materiais e simbólicos elaborados por todos os grupos sociais (GARCIA CANCLINI, 1994, pág. 96).

É importante a valorização da diversidade, das identidades e das manifestações culturais de épocas, de civilizações e de riquezas diversas. Esse pensamento também é compartilhado por TOLEDO (1984: p.39):

A busca da preservação de nossa identidade cultural é o objetivo primeiro de toda política de preservação dos bens culturais. Essa política nasce de um comprometimento com a vida social. $\mathrm{O}$ acervo a ser preservado, recebido de gerações anteriores ou produto do nosso tempo, será referido como histórico por sua significância, por sua maior representatividade social. Esse ordenamento tem, pois, como pressuposto o respeito à qualidade do meio ambiente e aos valores históricos, culturais e estéticos que dão a cada comunidade sua individualidade. Tais valores estão desvinculados do conceito de vulto, monumentalidade ou excepcionalidade.

Geografia Ensino \& Pesquisa, v. 17, n.1 p. 55-70, jan./abr. 2013

Figueiredo, L. C. 
Leniaud (1992, p. 01) também define patrimônio como "um conjunto de coisas do passado que são transmitidas às gerações futuras em razão de seu interesse histórico e estético". Varine-Bohan (1974, p. 04), sugeriu que o Patrimônio Cultural pode ser dividido em três grupos distintos e que estes três grupos juntos formam de maneira indissolúvel o que seria o Patrimônio Cultural, compondo o que ele chama de ecossistema do homem. 0 primeiro destes grupos engloba os elementos pertencentes à natureza: os rios, o clima, a vegetação, o solo, enfim, todos os recursos naturais que formam 0 ambiente natural e que tornam o sítio habitável.

O segundo grupo refere-se ao conhecimento, às técnicas e ao saber/fazer adquiridos, tudo aquilo que não pode ser medido nem quantificado, é a capacidade do homem de se adaptar ao meio-ambiente são os elementos não tangíveis do Patrimônio Cultural.

O terceiro grupo é aquele que por hábito chamamos de Patrimônio, ou seja, tudo aquilo que o homem ao interagir com o meio em que vive e usando os conhecimentos adquiridos fabricou ou construiu ao longo de sua existência. (LEMOS, 1981; VARINE-BOHAN, 1974).

Para os estudiosos da área do patrimônio essa terceira categoria é também subdividida em: bens mobiliários e imobiliários ou bens móveis e imóveis. Mas Varine-Bohan (1974, p. 06) refuta essa divisão alegando que para ele não existem diferenças de valor entre bens móveis e imóveis, pois tudo faz parte do Patrimônio Cultural, sendo as diferenças apenas físicas e não de valor. Existe uma evolução continua no conceito do que é Patrimônio Cultural. A própria Constituição Federal em vigor adota uma ótica mais abrangente reconhecendo o Patrimônio Cultural como a memória e o modo de vida da sociedade brasileira, juntando assim elementos materiais e imateriais. Constitui patrimônio cultural brasileiro os bens de natureza material e imaterial, tomados individualmente ou em conjunto, portadores de referência à identidade, à ação, à memória dos diferentes grupos formadores da sociedade brasileira, nos quais se incluem: I - as formas de expressão; II - os modos de criar, fazer e viver; III - as criações científicas, artísticas e tecnológicas; IV - as obras, objetos, documentos, edificações e demais espaços destinados às manifestações artístico-culturais; $V$ - os conjuntos urbanos e sítios de valor histórico, paisagístico, artístico, arqueológico, paleontológico, ecológico e científico. (BRASIL, 2002, p. 132).

Assim, outra definição de Patrimônio Cultural é possivel, como tudo aquilo que o homem criou e que por questões culturais inerentes ao meio em que se insere, muniu-se de valor para aquela sociedade. Cada bem cultural tem o seu próprio valor local e alguns adquirem também um valor mundial tornando-se dessa maneira Patrimônio Cultural da Humanidade.

Para Choay (2001, p 11) o Patrimônio Histórico é uma parte do Patrimônio Cultural. A expressão designa um bem destinado ao uso-fruto de uma comunidade que se ampliou a dimensões planetárias, constituído pela acumulação continua de uma diversidade de objetos que se agregam por seu passado comum: obras e obras-primas das belas artes e das artes aplicadas, trabalhos e produtos de todos os saberes e savoir-faire dos seres humanos.

Independente do seu valor histórico ou artístico, o patrimônio cultural pertence à comunidade que o herdou. Sua conservação é de fundamental importância para a memória coletiva da cidade.

\section{Evolução do Conceito de Patrimônio Cultural: o papel da UNESCO}

Ao longo do século $\mathrm{XIX}$, os países europeus organizaram estruturas governamentais e pri-

Geografia Ensino \& Pesquisa, v. 17, n.1 p. $55-70$, jan./abr. 2013

Perspectivas de análise geográfica do patrimônio cultural: algumas reflexões vadas voltadas para a seleção, a salvaguarda e a conservação dos patrimônios nacionais, até então composto, essencialmente, de objetos de arte e edificações estreitamente relacionadas à concepção de monumento histórico, aos ideais renascentistas de arte e beleza e aos conceitos de grandeza e excepcionalidade. Esses patrimônios eram, ao mesmo tempo, as riquezas das nações e a representação do seu gênio e história.

Um dos primeiros países europeus a criar uma legislação específica nesse sentido (voltados para a proteção, guarda e conservação dos bens patrimoniais) foi a França que até o inicio do sé- 
culo XX, trabalhou apenas com recenseamentos e inventários, sem instrumentos legais que a rigor, garantissem a preservação dos edifícios selecionados.

\section{As Cartas Patrimoniais}

A partir do século XIX um pensamento mais estruturado sobre a proteção do patrimônio cultural começa a ser organizado. Mas somente no início do século XX que posturas, legislações e atitudes mais abrangentes e concretas são postas em prática. São aproximadamente quarenta documentos, conhecidos como Cartas Patrimoniais, que registram a evolução do pensamento preservacionista e apresentam um panorama das diferentes abordagens que a questão da preservação recebeu ao longo do tempo. A origem do conceito moderno de preservação surgiu na década de 1930 quando intelectuais, cientistas e agentes governamentais sentiram a necessidade de instrumentos orientadores para a grande quantidade de restaurações e intervenções inadequadas que estavam sendo feitas após a I Guerra Mundial.

Em 1931, surge a Carta de Atenas, que discute a racionalização de procedimentos em arquitetura e propõe normas e condutas em relação à preservação e conservação de edificações, para terem caráter internacional e garantirem a perpetuação das características históricas e culturais nos monumentos a serem preservados.

As técnicas e as teorias dominantes a cada momento da evolução do pensamento preservacionista, muitas vezes possibilitaram a descaracterização de prédios de valor histórico, ao permitirem certas adaptações de técnicas construtivas ou ao consentirem na modernização de instalações para a readequação dos espaços às demandas da vida moderna. Os documentos gerados inicialmente, em geral, não têm maior grau de observância com a explicitação de detalhes para 0 restauro ou para outras intervenções nos monumentos de patrimônio histórico.

Assim, com a evolução do pensamento e frente a avaliações de casos ocorridos, outras regulamentações e orientações foram sendo editadas, no esforço de controle das modernizações que eram introduzidas pelas intervenções, e para o equacionamento de diretrizes de resgate da memória e da cultura na conservação do patrimônio edificado.

Uma maior e mais criteriosa abordagem sobre restauro aconteceu em 1964 com a elaboração da CARTA DE VENEZA - Carta Internacional do Restauro.

As cartas ao longo do tempo permanecem atuais e são complementadas por novas normas e recomendações que nos descortinam novos ou mais amplos procedimentos na preservação do patrimônio cultural.

Muitas Cartas, Recomendações e Leis propõem tipos de atitudes em relação aos bens patrimoniais, que é necessário analisarem os conceitos nelas contidos para uma atitude consciente na adoção de políticas preservacionistas do patrimônio.

Após a II Guerra Mundial, precisamente em 1945, foi criada a Organização das Nações Unidas para a Educação, a Ciência e a Cultura (Unesco - United Nations Educational, Scientific and Cultural Organization) e constitui-se na autoridade promotora da restauração a nível mundial. Dentre seu vasto campo de atividades nasceram instituições destinadas à promoção e à difusão de idéias e técnicas relacionadas à restauração, como por exemplo, o ICOM (Conselho Internacional de Museus), o ICC (Instituto Internacional para a Conservação de Trabalhos Históricos e Artísticos), o ICROM (Centro Internacional para o Estudo da Preservação e Restauração da Propriedade Cultural), entre outros. O Conselho Internacional de Monumentos e Sítios (ICOMOS - International Council on Monuments and Sites) é uma organização não governamental, com sede em Paris, voltada para a conservação dos monumentos e sítios históricos do mundo. Foi fundado em 1965, em conseqüência da Carta de Veneza e tem associados em vários países.

Na $12^{a}$ Conferência Geral da Unesco, realizada em Paris, foi lançada a Recomendação Relativa à Salvaguarda e Beleza e do Caráter das Paisagens e Sítios (1962). A Recomendação 26 entende por

Geografia Ensino \& Pesquisa, v. 17, n.1 p. 55-70, jan./abr. 2013

Figueiredo, L. C. 
salvaguarda da beleza e do caráter das paisagens e sítios a preservação da natureza ou da obra do homem, que apresentem um interesse cultural ou estético, ou que constituam meios naturais característicos (CURY, 2004). 0 mesmo autor adverte ainda que a salvaguarda não deva ser limitada apenas aos sítios naturais, mas abranger algumas paisagens e determinados sítios, tais como paisagens e sítios urbanos, que são, geralmente, os mais ameaçados, especialmente pelas obras de construção e pela especulação imobiliária e dever-se-ia proteger especialmente às proximidades dos monumentos.

Assim como afirmou a Carta de Veneza, a conservação de um monumento implica a preservação de uma ambiência em sua escala, sendo que toda a construção nova, toda destruição ou modificação que possam alterar as relações de volumetria e de cor será proibida (CURY, 2004. Tais definições foram sendo repetidas e reforçadas em sucessivos documentos, sendo que a partir da Declaração de Amsterdã (1975), é proposta a adoção da Conservação integrada, por meio da relação entre o Planejamento do uso do solo e Planejamento Urbano e Regional. A Declaração relata que o patrimônio arquitetônico compreende não somente as construções isoladas de um valor excepcional e seu entorno, mas também os conjuntos, bairros de cidades e aldeias que apresentem um interesse histórico e cultural (CURY, 2004). Alega também que o patrimônio arquitetônico é parte essencial da memória dos homens de hoje em dia e se não for possível transmiti-la às gerações futuras na sua riqueza autêntica e em sua diversidade, a humanidade seria amputada de uma parte da consciência de sua própria continuidade.

A noção de patrimônio cultural na Unesco adquiriu, com a evolução do tema, significado amplo e diversificado. Abrangem os monumentos históricos, conjuntos urbanos, locais sagrados, obras de arte, parques naturais, paisagens modificadas pelo homem, ecossistemas e diversidade biológica, tesouros subaquáticos, objetos pré-históricos, peças arquitetônicas e tradições orais e imateriais da cultura popular.

\section{Nova categoria de bem patrimonial: a paisagem cultural}

Entre outras a geografia foi à ciência humana que se interessou pelo estudo da paisagem, e dela surgiram duas correntes teóricas: a Geografia Cultural Tradicional que analisa a paisagem através de sua morfologia e a Nova Geografia Cultural que interpreta a paisagem com base em sua simbologia. Apesar de serem correntes opostas, ambas defendem que a paisagem é fruto da interação do homem com a natureza. A Geografia Cultural Tradicional teve como precursores os geógrafos alemães Otto Schuter e Passarge que analisam as transformações da paisagem oriundas da ação do homem, introduzindo na geografia o conceito de paisagem cultural, em oposição à paisagem natural. Seus estudos se detinham apenas aos aspectos morfológicos da paisagem.

O geógrafo americano Carl 0 . Sauer consolida a noção de paisagem como conceito científico, pode ser considerado o fundador da geografia cultural norte-americana. Em 1925, Sauer da inicio a investigação da paisagem como resultado da cultura humana. Em seu estudo "A Morfologia da Paisagem", o autor apresenta uma análise da paisagem em suas formas materiais, além de relacionar as formas naturais com os fatos culturais. (RIBEIRO, 2007). Tomando por base os conceitos desenvolvidos por Schluter e Passarge passa a incorporar na análise da paisagem o fator tempo, afirmando que o mesmo está em constante processo de transformação.

No final da década de 1960 surge uma nova corrente que valorizou a subjetividade na pesquisa geográfica e foi caracterizada como Nova Geografia Cultural. Segundo Ribeiro (2007), o movimento de renovação da geografia cultural teve o papel de incluir na agenda de pesquisa os as-

Geografia Ensino \& Pesquisa, v. 17, n.1 p. $55-70$, jan./abr. 2013

Perspectivas de análise geográfica do patrimônio cultural: algumas reflexões

621

ISSN 2236-4994 pectos intangiveis e subjetivos da paisagem. Dois de seus principais defensores, Augustin Berque e Denis Cosgrove. Berque afirmam que a importância do estudo da paisagem está no fato de que ela nos permite perceber o sentido do mundo no qual estamos, "defende a paisagem como marca e como matriz, marca porque expressa uma civilização, mas também é matriz porque participa dos esquemas de percepção, de concepção e de ação, ou seja, da cultura, os quais canalizam a relação de uma sociedade com o espaço e com a natureza". (BERQUE, 1998, p.78). 
Para Cosgrove a paisagem é percepção do mundo que tem sua própria história, mas esta só pode ser entendida como parte de uma história mais ampla da economia e da sociedade. Em uma perspectiva simbólica, o geógrafo afirma que "a paisagem é um conceito valioso para uma geografia efetivamente humana, pois ao contrário do conceito de lugar, lembra-nos sobre a nossa posição no esquema da natureza". (COSGROVE, 1998, p.42). Esta abordagem realizada a respeito dos conceitos da Geografia Cultural é fundamental, pois tais reflexões estão presentes nos estudos ligados à preservação do patrimônio cultural e da paisagem.

A idéia de Paisagem Cultural, buscando uma visão integrada entre o ser humano e a natureza iniciou na década de 1980, "em 1992 especialistas se reuniram na França, a convite do ICOMOS - Conselho Internacional de Monumentos e Sítios e do Comitê do Patrimônio Mundial da Unesco para pensar a forma como a idéia de paisagem cultural poderia ser incluída na lista do Patrimônio Mundial, visando à valorização da relação entre o ser humano e o meio ambiente, entre o cultural e o natural. Com isso, a Unesco passou a adotar três categorias diferentes de paisagem para serem inscritas como patrimônio: (RIBEIRO, 2007). a) Paisagem claramente definida: são classificados os parques e jardins. Pois são as paisagens desenhadas e criadas intencionalmente. b) Paisagem evoluída organicamente: paisagens que resultam de um imperativo inicial social, econômico, administrativo e/ou religioso e desenvolveu sua forma atual através da associação com o seu meio natural e em resposta ao mesmo. c) Paisagem cultural associativa: tem seu valor dado em função das associações que são feitas acerca delas, mesmo que não haja manifestações materiais da vida humana.

De sua proposição e evolução nas discussões geográficas, o conceito de Paisagem Cultural acaba sendo apropriado pela UNESCO em 1992, para representar bens patrimoniais de relevância internacional no qual se manifestava uma influência clara e mútua entre ação humana e meio ambiente. Passava-se assim, de uma concepção de patrimônio bipartida entre bem natural e bem cultural, para uma noção de patrimônio misto, integrado e interdependente, num processo lento da consideração do valor cultural de paisagens naturais (RIBEIRO, 2007).

Antes desse período, a paisagem já constava em documentos de natureza patrimonial, porém analisada ora sob o aspecto de entorno, de ambiência de determinado bem, geralmente arquitetônico, ora por sua qualidade estética ou por sua importância exclusivamente natural.

Fowler (2003), explica que o conceito de paisagem cultural pode servir para o reconhecimento de estruturas ligadas a sociedades tradicionais, historicamente marginalizadas na atribuição de valor como patrimônio mundial.

Do Projeto da Convenção Européia de Paisagem, consta a seguinte definição: "paisagem designa uma parte do território tal qual percebido pelas populações, cujo caráter resulta da ação de fatores naturais e/ou humanos e de suas inter-relações" (PORTUGAL, 2008).

No Brasil o Instituto do Patrimônio Histórico e Artístico Nacional - IPHAN, através da Portaria $n^{0}$ 127, de 30 de abril de 2009, estabelece a chancela da Paisagem Cultural Brasileira como uma porção peculiar do território nacional, representativa do processo de interação do ser humano com o meio natural, em que a vida e a ciência humana imprimiram marcas ou atribuíram valores (BRASIL, 2009).

A paisagem como um bem patrimonial, figura no cenário nacional desde a elaboração da Constituição de 1988. Considerados Patrimônio Cultural Brasileiro, entre outros, os "conjuntos urbanos e sítios de valor histórico, paisagístico, artístico, arqueológico, paleontológico, ecológico e científico" (BRASIL, 1988, p. 42). Além disso, desde a criação do principal órgão federal responsável pela proteção e preservação do patrimônio cultural brasileiro, o IPHAN (então SPHAN - Serviço do Patrimônio Histórico e Artístico Nacional), a preocupação com elementos e sítios naturais já figura na legislação patrimonial brasileira. O Decreto-lei $n^{0} 25$, de 1937, que cria a referida Instituição, faz referência aos "monumentos naturais bem como aos sítios e paisagens que importe conservar e proteger pela feição notável com que tenham sido dotados pela natureza ou agenciados pela indústria humana" (IPHAN, 1937, p. 01).

Entretanto, nas duas visões, a importância e valor patrimonial se atribuíam ou às características físicas naturais do bem, ou à sua representatividade como ambiência ou entorno de um

Geografia Ensino \& Pesquisa, v. 17, n.1 p. 55-70, jan./abr. 2013

Figueiredo, L. C.

ISSN 2236-4994 
bem principal, geralmente arquitetônico. Durante esse período, a preocupação com o patrimônio brasileiro mostrava-se bipartida, ao ser compreendido e dividido entre patrimônio cultural e patrimônio natural, predominando uma dissociação entre as concepções de cultura e natureza. Segundo Meneses (2002), muitas vezes a consideração da paisagem como patrimônio ocorreu pelo processo de monumentalização que toma elementos da paisagem e os transforma em fetiches sacralizados, dotados de valores próprios, como se fossem autônomos, imutáveis, independentes das contingências das esferas sociocultural, independentes, também, do próprio contexto ambiental. "Ao sobressair, o monumento assume, sozinho, os significados dispersos no espaço de que faz parte" (MENESES, 2002, p. 50).

A partir do desenvolvimento da consciência ambientalista e a preocupação com a preservação de áreas naturais, juntamente com a nova noção de desenvolvimento sustentável, estabelece-se uma nova relação entre homem e meio ambiente, que passará a permear a sociedade e propor novas formas de desenvolvimento, valorizando a harmonia entre homem e meio ambiente. A natureza passa, assim, de fonte de subsistência, à mercantilização e transformação matéria-prima com a economia capitalista, para uma nova concepção que a consagrará como bem patrimonial.

A criação da nova categoria de bem patrimonial no Brasil apropriou-se da experiência da UNESCO-ICOMOS, que desde 1992 incluiu a Paisagem Cultural como um bem patrimonial dentre os demais na Lista do Patrimônio Mundial. De acordo com o ICOMOS (2009), a inscrição de Paisagem Cultural como bem se justifica por ser ilustrativa da trajetória histórica da sociedade humana e seus assentamentos sob a influência de contingências físicas e/ou oportunidades apresentadas pelo ambiente natural, bem como pelas sucessivas forças social, econômica e cultural, que nelas interferem. São valorizados assim, a interação homem e meio ambiente e a continuidade dos valores e funções a ele associados, assim como os valores afetivos estabelecidos com o território (MENESES, 2002).

No Brasil, a categoria de Paisagem Cultural fora oficialmente criada pelo IPHAN em 2009, pela Portaria $n^{0} 127$. Entre os motivos justificadores da adoção da Paisagem Cultural como bem patrimonial está a preocupação com os fenômenos contemporâneos de expansão urbana, globalização e massificação das paisagens rurais e urbanas. Além disso, a nova categoria de bem cultural viria sanar a deficiência de instrumentos de proteção que contemplem e abarquem integralmente o conjunto de componentes e a complexidade implícita na composição da paisagem cultural, uma vez que a maioria dos dispositivos legais referentes ao patrimônio os toma individualmente em sua dimensão natural e cultural.

Sob a perspectiva do IPHAN, o objetivo da declaração de Paisagem Cultural é conferir um selo de reconhecimento a porções do território nacional, onde a inter-relação entre a cultura humana e 0 ambiente natural confere à paisagem uma identidade singular. É definida como "uma porção peculiar do território nacional, representativa do processo de interação do homem com o meio natural, à qual a vida e a ciência humana imprimiram marcas ou atribuíram valores" (DIÁRIO OFICIAL DA UNIÃO, 2009, p. 17).

Essa nova categoria de bem patrimonial brasileiro fora antecedida por alguns encontros técnico-científicos que ocorrem desde 2007, promovidos pelo IPHAN em parceria com instituições de ensino e sociedade em geral. A Carta de Bagé ou Cartas das Paisagens Culturais, documento que é referência na discussão da Paisagem Cultural no Brasil, é originária da Jornada "Paisagens Culturais: novos conceitos, novos desafios", encontro realizado em agosto de 2007, em Bagé (RS), que integrou a programação do Seminário Semana do Patrimônio - Cultura e Memória na Fronteira. A Carta de Bagé tem por objetivo "a defesa das paisagens culturais em geral e, mais especificamente, do território dos Pampas e das paisagens culturais de fronteira" (IPHAN et al., 2007, p. 01).

A Paisagem Cultural Brasileira é assim definida como o meio natural ao qual o ser humano imprimiu as marcas de suas ações e formas de expressão, resultando em uma soma de todos os testemunhos resultantes da interação do homem com a natureza e, reciprocamente, da natureza com o homem, passíveis de leituras espaciais e temporais (IPHAN et. al., CARTA DE BAGÉ, 2007, geográfica do patrimônio cultural: algumas reflexões p. 02). 
Diante das diversas definições de paisagem, pode-se considerar ainda a paisagem como 0 território definido por suas características naturais e intervenções antrópicas, onde o ser humano habita e se relaciona com o ambiente, e que, além de valores ecológicos e descrições geográficas, tem significados sociais e culturais, e pode ser vista sob os seus aspectos estéticos ou cênicos.

\section{O valor de uso da preservação patrimonial: um olhar geográfico}

O Patrimônio Arquitetônico, também chamado de Patrimônio Edificado, diz respeito como o próprio nome sugere as edificações que adquiriram significação histórica e cultural em determinada sociedade. A sua preservação sempre ocorre no sentido de selecionar os exemplares mais expressivos, preciosos e representativos de determinado estilo arquitetônico. (IPHAN, 2003, p. 07).

Junto ao Patrimônio Arquitetônico existe outra categoria, a do Patrimônio Urbano. Segundo Choay (2001, p. 179) a transformação da cidade material em objeto de conhecimento histórico foi influenciada pelas mudanças ocorridas no espaço urbano logo após a revolução industrial. Os primeiros estudos sobre as cidades antigas surgiram quando houve a necessidade de estudar e compreender as mudanças ocorridas na cidade contemporânea. A importância de se preservar 0 patrimônio de uma cidade e do seu entorno está no fato de que essa é a única maneira como a população consegue fazer uma leitura continuada sobre a história em que ela está inserida, ou seja, a história que ela recebeu de seus antepassados; se reconhecer e fazer uma leitura no contexto atual do presente para projetar seu futuro e das próximas gerações.

Essa leitura é defendida por Lefèbvre (1991) ao sinalizar que o conflito pelo uso do espaço é a essência do processo social, no qual a propriedade privada torna-se um empecilho à apropriação concreta de um tempo e de um espaço, e o espaço torna-se um dado no qual se inscreveu a história da sociedade que o tomou por objeto, integrando o processo de valorização como propriedade. Logo, a importância do espaço é dada pela dialética entre valor de uso e valor de troca, que produz espaço social de usos e espaços abstratos de expropriação. Assim como não tem apenas valor de troca, econômico, também não é apenas um instrumento político que visa homogeneizar a sociedade. $O$ espaço continua sendo um protótipo permanente do valor de uso, que se opõe às generalizações do valor de troca na economia capitalista sob a autoridade de um Estado homogeneizador.

Portanto, quando se discute sobre a importância da preservação de espaços urbano/rurais, ou que deles derivam sua dinâmica, se discute a preservação dos valores de uso. Se os espaços forem destinados somente à troca, ou seja, transformados em mercadoria, sua apropriação e modo de uso será subordinado ao mercado. Sendo assim, esses espaços transformados em mercadoria ou apenas em áreas de circulação diminuirão, limitando seu uso às formas de apropriação privada, cada vez mais restrita a lugares vigiados, normatizados, privados ou privatizados (LEFĖBVRE, 1972).

Porém, como um depende do outro, a dialética entre os valores de uso e de troca tende a se estabilizar de acordo com os interesses predominantes em determinados momentos.

O espaço aparece como obra histórica que se produz a partir das contradições existentes na sociedade e suas relações sociais como dominação, subordinação e uso e apropriação, que o traduz apenas como valor de troca e mercantilização do solo. Porém atualmente a reprodução das relações sociais se processa pela lógica de ações políticas, pelo controle sobre a técnica e o saber, e pela presença contraditória do Estado hegemônico no espaço, que determina essas relações sociais e de produção por meio da reprodução do espaço, como ação planejada. Essa reprodução espacial se desenvolve em uma sociedade hierarquizada, mas que produz de forma socializada (LEFÈBVRE, 1972).

A localidade se estrutura justamente entre o desejo da sociedade e o que é necessário para o processo de reprodução do capital. 0 espaço é o local de reprodução das relações sociais em nossa sociedade, que não aparece na totalidade, mas fragmentado, tal e qual como a sociedade se reproduz em nosso país. Essa fragmentação das classes sociais e do espaço é articulada por pla-

Geografia Ensino \& Pesquisa, v. 17, n.1 p. $55-70$, jan./abr. 2013

Figueiredo, L. C.

ISSN 2236-4994 
nos econômicos, políticos e sociais que visam à passagem do processo de valor de uso para valor de troca. Considerando que o espaço não deve ser apenas uma mercadoria e o cidadão não deve ser apenas força de trabalho, o espaço geográfico como produção social que se materializa formal e concretamente deve ser algo passível de ser apreendido, entendido e apropriado pela sociedade, como condição para a reprodução da vida ao longo da história (LEFĖBVRE, 1991).

A preservação do patrimônio edificado e da memória é contrária à lógica capitalista, que pretende transformar o espaço em mercadoria, sobrepondo-a somente ao valor de troca em detrimento do seu real valor de uso. Para Lefèbvre (1991) a própria localidade é uma obra que se opõe ao valor apenas de troca, pois a obra é valor de uso e o produto é valor de troca. Ela possui um conjunto significante, que apesar das sucessivas intervenções ou agressões na sua paisagem, tem o potencial de reconstituir-se, como linguagem, a partir de seus referenciais reconstruídos e evocar o passado de forma reflexiva, como ambiente de recuperação de uma identidade social presente.

Reconstituir a memória de um determinado lugar não significa apenas valorizar as lembranças mortas ou individuais através de textos, imagens ou espetáculos teatrais como sempre foi feito e inclusive permanece até hoje. Significa então, intervir nas ações de determinados sujeitos sociais, substituindo a fútil ocupação intensiva pela preservação dos espaços que ainda representam uma identidade, valorizando a memória urbana da coletividade e deixando-a viva, num processo cuja lógica de mercado necessite do real valor de uso dessa obra.

Essa obra nasce da história e é preciso apreendê-la em sua multiplicidade, pois constitui um acervo de situações, necessidades, aspirações e desejos que se realizam como possibilidades. Para Lefèbvre, é na vida cotidiana que esse acervo forma um conjunto e ganha sentido, forma e constituição. A vida cotidiana se define como totalidade, dependente de todas as atividades do ser humano, seus conflitos e suas diferenças, não se limitando apenas às relações de produção de mercadorias. Espaços de sociabilidade evocam os mitos fundadores de uma coletividade e por isso devem ser preservados.

Preservar significaria uma resistência ao processo de expropriação que as forças econômicas efetuam sistematicamente sobre determinados espaços (FIGUEIREDO, 2005).

Nesse contexto, a preservação do patrimônio e da memória é algo em disputa, de um lado a busca pelas origens e identidades verdadeiras e do outro lado, com o apoio institucional, novas perspectivas pré-determinadas se impõem com uma nova imagem, pressupostamente durável, que visam se sobrepuser aos espaços anteriores, concretizando assim o seu discurso e sua ideologia. Desse modo esses espaços perderiam seu verdadeiro conceito de obra, substituindo seu real valor de uso pela expropriação do valor de troca.

Os discursos progressistas pregam que diversos lugares devem estar inseridos no mundo globalizado, como as metrópoles, e sendo assim, os lugares mais antigos tornam-se obstáculos para o seu "crescimento" e por isso devem ser liquidados ou substituídos. É justamente o contrário do que Milton Santos defendia, quando tratava da importância da permanência das rugosidades na produção do espaço urbano, pois "o estudo da paisagem pode ser assimilado a uma escavação arqueológica" (SANTOS, 1985, p.55). Para Santos, as rugosidades são as heranças espaciais produzidas em um determinado período histórico, de um determinado modo de produção desse período, e por isso, possuem características sociais e culturais específicas. (SANTOS, 1978). Nesse sentido, quanto maior for o número de rugosidades marcadas na paisagem, preferencialmente no espaço físico, mais fácil será para se fazer uma leitura da construção dessa paisagem através dos diferentes períodos e modos de produção nos quais o espaço foi culturalmente produzido, contribuindo assim, para a formação da memória urbana de uma coletividade.

Importa lembrar ainda não ter sentido encarar a memória como uma realidade congelada ou paralisada no tempo. Daí a necessidade de adotar cautelas necessárias objetivando não recair em interpretações equivocadas. Para defender, proteger ou preservar um testemunho arqueológico ou um monumento tem-se que considerar não só o valor histórico e patrimonial, mas também a relação 


\section{Considerações finais}

A multiplicidade de remanescentes do passado inscritos no tempo presente faz do campo da preservação do patrimônio um ambiente plural e heterogêneo.

A defesa do patrimônio histórico adentrou nas últimas três décadas á agenda de amplos setores da sociedade brasileira. A criação de órgãos de defesa do patrimônio no âmbito dos municípios e estados ou a mobilização de vários setores da sociedade civil com vistas á preservação de bens materiais e imateriais em várias cidades e o conseqüente tombamento de muitos edifícios, residências e bairros assim como as formas de expressão, os modos de criar, saber/fazer e viver..., são alguns exemplos que explicitam a importância desta questão no Brasil. Ė preciso considerar, que a defesa do patrimônio produz um campo de disputa que envolve as Universidades, setores governamentais, comunidades as mais diversas, ambientalistas, organizações não governamentais, agentes do capital, dentre outros. Desta disputa, erigem-se práticas diversas acerca da preservação, noções sobre a memória e percepções sobre a idéia de cultura.

Se a visibilidade das questões que envolvem a preservação do patrimônio histórico traz um sentido positivo - no que se refere ás possibilidades de reconhecimento dos remanescentes do passado vivido presente - é necessário considerar que se está diante de estratégias que disputam a participação na construção da memória social.

O que foi exposto permite inferir que as possibilidades da dimensão geográfica cultural contemporânea na geografia são múltiplas. Em especial o patrimônio histórico e cultural, referências culturais dos grupos humanos presente nas cidades. Mesmo sem tradição nos estudos geográficos, os bens culturais em suas mais diversas problematizações, merecem mais atenção por parte dos geógrafos, notadamente no que tange ao diálogo constante (ainda pouco utilizado) com áreas afins. A partir de olhares multifocados somadas a ações conjuntas e coordenadas, facilita a a formação e consolidação da consciência da preserาvação desse patrimônio, como legado da constituição da sociedade brasileira. $O$ resultado é um conjunto harาmônico de reflexões inovadoras ou inspiradoras sobre nossos bens culturais.

Nessa mesma direção os estudos de Maurício de Abreu (1994, p.43-59) intitulado "A cidade da Geografia no Brasil: percurso, crises e superações" ao discutir o processo de crescimento e amadurecimento da disciplina de geografia no Brasil, salientam ser reconfortante constatar que a "era das revoluções" está, hoje, definitivamente encerrada na geografia brasileira. Para o autor as diferentes matrizes epistemológicas convivem civilizadamente no interior da disciplina, a reflexão teórica avança a passos largos na tentativa de preencher o vácuo deixado por décadas de empirismo, por tentativas apressadas de teorização neopositivista, pelos excessos do materialismo histórico, ou pelo dispêndio exagerado de energia na tentativa de impor um paradigma sobre os demais. "Temos hoje, portanto, uma geografia mais diversificada e não menos polêmica. Por isso mesmo, mais rica". (ABREU, 1994, p. 59).

\section{Referências}

ABREU, Mauricio de Almeida. O estudo geográfico da cidade no Brasil: evolução e avaliação (contribuição à história do pensamento geográfico brasileiro). In: CARLOS, Ana Fani A. (org.). Os caminhos da reflexão sobre a cidade e o urbano. São Paulo, Edusp. 1994, p. 43-59.

ABREU, Maurício de Almeida. Sobre memória das cidades. Revista Território, Rio de Janeiro: v.3,n.4, jan/jun, 1998.

Geografia Ensino \& Pesquisa, v. 17, n.1 p. 55-70, jan./abr. 2013

BERQUE, Augustin. Paisagem-Marca, Paisagem-Matriz: Elementos da Problemática para uma Geografia Cultural. In: CORREA,Roberto Lobato e ROSENDAHL, Zeny. Paisagem, Tempo e Cultura. Rio de Janeiro: EdUERJ, 1998. 
BURKE, Peter. A Escola dos Annales (1929-1989). São Paulo: UNESP, 1991.

BURDA, Naomi Anaue; MONASTIRSKY, Leonel Brizolla. URBE - Revista Brasileira de Gestão Urbana, Curitiba: v.3, n.1, p. 115-123, jan./jun. 2011.

BRASIL. Portaria $n^{\circ} 127$, de 30 de abril de 2009. Estabelece a Chancela da Paisagem Cultural. Diário Oficial da União, 5 maio 2009. Seção 1, p. 17.

CARTIER-BRESSON, Henri. O momento decisivo. In: Fotografia e Jornalismo. Bacellar, Mário Clark (org.). São Paulo, Escola de Comunicações e Artes (USP), 1971, pp. 19-26.

CIFELLI, G. Turismo, patrimônio e novas territorialidades em Ouro Preto - MG. 2005. 245 f. Dissertação (Mestrado em Geografia) - Instituto de Geociências, Universidade Estadual de Campinas, Campinas, 2005.

CHARTIER, Roger . verbete imagens. In: BURGUIĖRE, André. Dicionário das ciências históricas. Rio de Janeiro: Imago, 1992, p.407.

CLAVAL, Paul. A Geografia Cultural: 0 estado da arte. In: CORREAA, Roberto Lobato; ROSENDAHL, Zeny. (Orgs.). Manifestações da cultura no espaço. Rio de Janeiro: EdUERJ, 1999.

A Geografia Cultural. Tradução de Luiz Fugazzola Pimenta e Margareth de Castro Afeche Pimenta. Florianópolis: UFSC, 2002.

CORRÊA, Roberto Lobato.. A dimensão cultural do espaço: Alguns temas. Espaço e Cultura, Rio de Janeiro, UERJ, ano 1, out. 1995b. Disponível em <http://www.nepec.com.br/2lobato. pdf>. Acesso em 08 out. 2009.

COSGROVE, Denis. A geografia está em toda parte: cultura e simbolismo nas paisagens humanas. In: CORREA, Roberto Lobato e ROSENDAHL, Zeny. Paisagem, Tempo e Cultura. Rio de Janeiro: EdUERJ, 1998, p.100.

FIGUEIREDO, Lauro César. Permanências e memórias da urbe: descobrindo a cidade de Santa Maria-RS a partir da fotografia. In Anais. IX ENANPEGE, Encontro Nacional da Associação Nacional de Pós-Graduação e Pesquisa em Geografia, Goiânia de 8 a 12 de outubro de 2011. A PESQUISA E A PRODUÇÃO GEOGRÁFICAS: o pulsar no tempo e no espaço. GT 08 Espaço e cultura: sustentabilidade cultural, paisagens culturais e espaços festivos, ISSN: 2175-8875,17p.

A memória urbana esquecida no tempo: o centro histórico da cidade de Santa Maria no Rio Grande do Sul. In: Anais. XII SIMPURB, Simpósio Nacional de Geografia Urbana, Belo Horizonte de 16 a 20 de novembro de 2011.a. CIÊNCIA E UTOPIA: por uma geografia do possível. Sessão 01 Paisagem e Memória Urbana, ISSN 2175-8875, 16p.

LEFEBVRE, Henri. O direito à cidade. São Paulo, Moraes, 1991.

A vida cotidiana no mundo moderno. São Paulo, Ática, 1991.a

Geografia Ensino \& Pesquisa, v. 17, n.1 p. 55-70, jan./abr. 2013

Perspectivas de análise geográfica do patrimônio cultural: algumas reflexões
A revolução urbana. Belo Horizonte: Ed. UFMG, 1979.

Espacio y política. Barcelona: Península,1976.

MARTINS, Guilherme d'Oliveira. Patrimônio, Herança e Memória: a cultura como criação. Coleção Trajectos Portugueses, 2 ed., Lisboa: Gradiva, 2009, pp. 07-14 
MONASTIRSKY, Leonel Brizolla. Ferrovia: Patrimônio Cultural: estudo sobre a ferrovia brasileira a partir da região dos campos Gerais (PR). Tese de Doutorado. Florianópolis: UFSC/CFH/PPGGeo,2006.

MONASTIRSKY, Leonel Brizolla. Espaço urbano: memória social e patrimônio cultural.Revista Terra Plural, Ponta Grossa: v.3, n.2, p.323-334, julh/dez.2009.

MONASTIRSKY, Leonel Brizolla; SANTOS, Edvanderson Ramalho dos. Operário Ferroviário Esporte Clube: patrimônio cultural de Ponta Grossa.Revista RA'EGA - o espaço geográfico em análise, Curitiba: n.24, pp. 52-68, 2011.

PAES-LUCHIARI, Maria Tereza Duarte. Patrimônio cultural: uso público e privatização do espaço urbano. In: Revista GEOGRAFIA, AGETEO/UNESP, Vol. 31, N. 01, Jan./Abril, Rio Claro, 2006. pp 44-66.

Centros históricos - mercantilização e territorialidades do patrimônio cultural. In: GE-

Ographia, Revista de pós-graduação em Geografia, N. 15, UFF/R.J, 2005

A reinvenção do patrimônio arquitetônico no consumo das cidades In: GEOUSP Espaço e Tempo, N. 17, São Paulo, 2005.a.

Patrimônio cultural, turismo e identidades territoriais - um olhar geográfico. Disponível em : < http://egal2009.easyplanners.info/area08/8118 Maria Tereza Duarte Paes.pdf. Acesso em 20 de junho de 2012.

PIMENTA, Margareth de Castro Afeche; PIMENTA, Luiz F. Afeche. Projeto patrimônio vivo. Revitalização do centro histórico de Florianópolis-SC. In: Anais do V Seminário Historia da Cidade e do Urbanismo.Campinas-SP: FAU-PUC , 1998, p. 35.

PIMENTA, Margareth A.C; PIMENTA, Luís Fugazzola. O lugar: patrimônio e memória urbana. Possibilidades de uma documentação. In: Leonardo Barci Castriota (org.). III Simpósio Temático: Rede Latino-Americana de acervos de arquitetura (RELARQ). Belo Horizonte, 2011, p.15-29.

RIBEIRO, Rafael Winter. Paisagem cultural e patrimônio. Rio de Janeiro: IPHAN/COPEDOC, 2008.

ZANATTA, Beatriz Aparecida. A Abordagem Cultural na Geografia. Temporais (ação) (UEG), v.1, p. 249-262, 2008. Disponível em: <http://www.nee.ueg.br/seer/index.php/temporisacao/article/ view/28/45>. Acesso em: 30 abr. 2011.

ZANIRATO, Silvia Helena; RIBEIRO, Wagner Costa. Patrimônio cultural: a percepção da natureza como um bem não renovável. Revista Brasileira de História, São Paulo, v. 26, n. 51, 2006 


\section{Correspondência:}

Lauro Cesar Figueiredo- Rua Dr. Liberato Salzano, Vieira da Cunha, 435, apto 201.

E-mail: laurocfigueiredo@hotmail.com

Recebido em 09 de outubro de 2012.

Aceito para publicação em 21 de janeiro de 2013.

Geografia Ensino \& Pesquisa, v. 17, n.1 p. 55-70, jan./abr. 2013

Perspectivas de análise geográfica do patrimônio cultural: algumas reflexões 